\title{
Optimised production of tailored syngas from municipal solid waste (MSW) by sorption-enhanced gasification
}

\author{
Isabel Martínez*, Gemma Grasa, Maria S. Callén, Jose Manuel López, Ramón Murillo \\ Environmental Research Group, Instituto de Carboquímica (Spanish National Research Council, ICB-CSIC), Miguel Luesma Castan 4, 50018 Zaragoza, Spain
}

\section{H I G H L I G H T S}

- Sorption enhanced gasification is successfully demonstrated for a MSW-based fuel.

- Gasification temperature is the variable that most influenced syngas composition.

- $\mathrm{CaO}$ carbonation influences $\mathrm{H} 2 / \mathrm{CO} / \mathrm{CO} 2$ proportion depending on the temperature.

- Biomass conversion is successfully correlated with temperature and residence time.

- Tar composition and yield are evaluated for different temperatures and $\mathrm{CaO}$ excess.

\section{A R T I C L E I N F O}

\section{Keywords:}

Waste to chemicals/fuel

Municipal solid waste

Steam gasification

In-situ $\mathrm{CO}_{2}$ removal

$\mathrm{CaO}$

Bubbling fluidised bed

\begin{abstract}
A B S T R A C T
Sorption-enhanced gasification (SEG) is a promising indirect gasification route for the production of synthetic fuels since it allows the $\mathrm{H}_{2}, \mathrm{CO}$ and $\mathrm{CO}_{2}$ content of the resulting syngas to be adjusted. This SEG process has been successfully demonstrated at pilot scale for lignocellulosic biomass and other agricultural and forest waste products, mainly focusing on $\mathrm{H}_{2}$-rich gas production. Within this work, the potential application of the SEG process to a material derived from municipal solid waste (MSW) as feedstock is experimentally demonstrated in a $30 \mathrm{~kW}_{\text {th }}$ bubbling fluidised-bed (BFB) gasifier. The influence of the sorbent-to-biomass ratio, steam excess and gasification temperature has been carefully analysed in order to understand their effect on SEG performance. Moreover, main conditions able to affect the resulting syngas composition, specifically in terms of $\mathrm{H}_{2}$, $\mathrm{CO}$ and $\mathrm{CO}_{2}$ content, have been indicated. Gasification temperature turned out to be the variable that most influenced syngas composition due to the limiting mechanisms associated with the carbonation of the $\mathrm{CaO}$ used as bed material. This operating variable also determined biomass conversion, together with solids residence time in the gasifier, resulting in a wide variation of fixed carbon conversion under the studied conditions. Finally, tar yield and composition were evaluated as a function of temperature and the sorbent-to-biomass ratio used, resulting in tar contents as low as $7 \mathrm{~g} / \mathrm{Nm}^{3}$ (dry gas), consisting mainly of 1-ring aromatic compounds.
\end{abstract}

\section{Introduction}

Waste disposal is one of the biggest problems faced by humankind. In 2018, 251 million tonnes of municipal solid waste (MSW) was produced in Europe, which corresponded to an average of $489 \mathrm{~kg}$ of MSW per capita in the same year [1]. The trend in recent years has been to reduce the amount of MSW produced as well as reducing its disposal in landfills (from 145 to 57 million tonnes between 1995 and 2018), while increasing the percentage that is finally incinerated, recycled or turned into compost. However, despite these efforts, there was only a $6 \%$ decrease in the MSW produced in European countries between 2008 until 2018 [1]. Based on these numbers, the most recent European Union action plan has stressed the importance of MSW in enhancing the development of a circular economy, not only through the use of and reduction of waste, but also by making MSW into products that will not be turned back into waste again [2]. In this sense, the waste-to-chemicals valorisation route may be a potential alternative to landfilling or incineration, which represented $23 \%$ and $28 \%$, respectively, of the MSW generated in Europe in 2018 [1], and thus play an important role in the circular economy. This conversion route could also have important advantages in terms of cost savings compared to the production of chemicals and fuels from alternative sources of biomass, since MSW requires collection and disposal regardless [2]. Moreover, it would reduce and finally do away with the need to use fossil fuels for the

\footnotetext{
* Corresponding author.

E-mail address: imartinez@icb.csic.es (I. Martínez).
} 


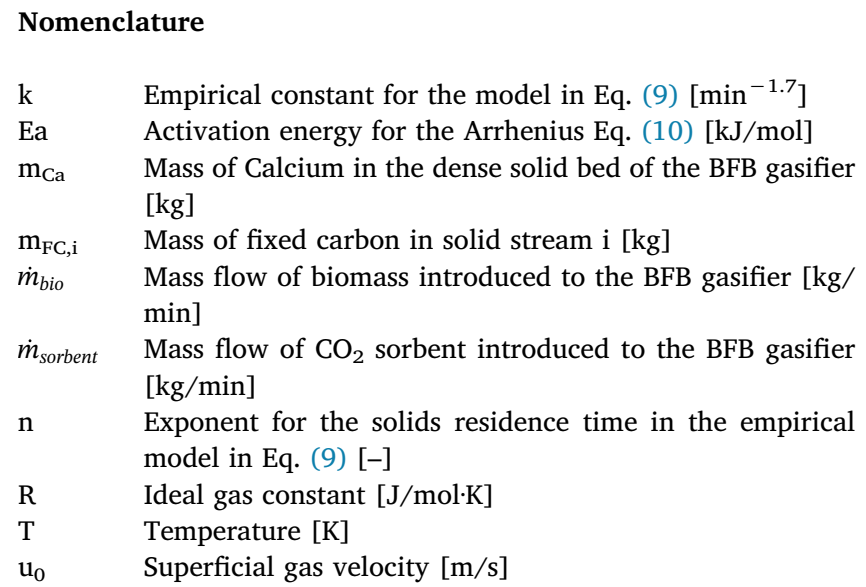

$\mathrm{u}_{\mathrm{mf}} \quad$ Minimum fluidisation velocity $[\mathrm{m} / \mathrm{s}]$

$\mathrm{X}_{\mathrm{FC}} \quad$ Fixed carbon conversion [-]

$\mathrm{y}_{\text {ash,bio }} \quad$ Mass fraction of ashes in the biomass [-]

$\mathrm{y}_{\mathrm{Ca}, \mathrm{i}} \quad$ Mass fraction of Calcium in the solid stream i [-]

Greek symbols

$\tau_{\mathrm{s}} \quad$ Solids residence time [min]

Subscripts

$\begin{array}{ll}\text { bed } & \text { solid bed } \\ \text { bio } & \text { biomass } \\ \text { cyc } & \text { cyclones } \\ \text { FC } & \text { fixed carbon } \\ \text { OF } & \text { overflow }\end{array}$

production of these chemicals, reducing the dependence on these fuels while also reducing the carbon footprint of those sectors.

Syngas production is the first step in the waste-to-chemical conversion route. Syngas refers to the gas mixture mainly comprising $\mathrm{H}_{2}$, $\mathrm{CO}$ and $\mathrm{CO}_{2}$, which is an intermediate used for the production of hydrogen, ammonia, methanol, ethanol and synthetic hydrocarbons. If the focus is that of producing a high quality syngas suitable for a catalytic process, it is important that resulting syngas is free of contaminants, tars and nitrogen, the last of these being the most difficult to remove from syngas products [3]. Allothermal or indirect gasification [4] is one of the most suitable and cost-effective thermochemical routes that allow $\mathrm{N}_{2}$-free syngas to be produced. In this gasification process, steam is typically used as the gasification agent, and heat for the endothermic gasification reactions can be provided either externally (by plasma or heat pipes), or internally by cooling a hot solid stream in a fast internally circulated fluidised bed or in a dual fluidised bed (DFB) system [5]. In this last configuration, unconverted char from the gasifier and a secondary fuel (if needed) are burnt with air in a separate fluidised bed reactor to provide heat to an inert material (e.g. sand or olivine), which is then transferred to the steam-blown gasifier to supply the required heat. In this sense, there is no need for an air separation unit for $\mathrm{O}_{2}$ production, thus reducing plant costs [3]. This DFB gasification concept has been demonstrated in different plants at commercial scale [6-11], as well as at smaller lab-scale facilities for a wide variety of residual feedstocks [12-14].

When a $\mathrm{CO}_{2}$ sorbent such as calcined limestone or dolomite is used as the circulating material in this DFB process, the sorption-enhanced gasification (SEG) process, shown in Fig. 1, is the result. In this case, $\mathrm{CaO}$ is introduced at high temperature together with biomass and steam into the gasifier, which is usually operated at temperatures of between $650{ }^{\circ} \mathrm{C}$ and $750{ }^{\circ} \mathrm{C}$. Endothermic gasification reactions are sustained by means of the hot $\mathrm{CaO}$ circulating solid stream as well as by the exothermic carbonation reaction occurring inside the gasifier. Operation at lower temperatures than for conventional indirect gasification with sand or olivine allows a reduction in the solid circulation between reactors in the DFB process $[15,16]$. This SEG process has been already demonstrated in various pilot and industrial-scale plants throughout Europe using wood or coal as feedstocks [17], and under conditions suitable for achieving $\mathrm{H}_{2}$ contents in syngas as high as 70-76 vol\% (dry basis) $[18,19]$. However, if the focus is on synthetic fuel production, the ratio of $\mathrm{H}_{2}, \mathrm{CO}$ and $\mathrm{CO}_{2}$ in the syngas should be adjusted according to the desired end product and the type of catalyst to be used in the synthesis reactor. Typically, the $\mathrm{H}_{2} / \mathrm{CO}$ ratio is modified by means of different water-gas shift (WGS) reactors operating at different temperatures, while the $\mathrm{CO}_{2}$ content is regulated through a $\mathrm{CO}_{2}$ separation process, e.g. by chemical or physical absorption. However, the possibility of acting on SEG operating parameters in order to obtain a syngas with the correct ratio of $\mathrm{H}_{2}, \mathrm{CO}$ and $\mathrm{CO}_{2}$ according to the desired end product would noticeably simplify the process [17], avoiding in this way the need for previously mentioned conditioning reactors and resulting in lower process costs. Moreover, this flexibility would allow synergy to be used with other renewable energy sources in a power-togas scheme, producing renewable hydrogen through electrolysis that can be mixed with the syngas downstream from the gasifier, whose operation has been modified to produce syngas with a higher $\mathrm{C}$ content. The potential for the flexible operation of this SEG concept has been assessed in the literature for a synthetic natural gas (SNG) production plant [20]. Modifying the operating temperature and solid circulation between reactors in the SEG process results in different scenarios of $\mathrm{CaO}$ and biomass conversion in the gasifier, which influence the energy balance in the combustor/calciner and therefore the efficiency of the entire process.

Within this framework, the objective of this study was to investigate experimentally the applicability of a MSW-derived material as feedstock for the sorption-enhanced gasification (SEG) process. Demonstrating the feasibility of this flexible gasification process for such problematic waste turns essential for its valorisation into valuable chemical products or synthetic fuels. SEG tests were performed in a 30 $\mathrm{kW}_{\text {th }}$ bubbling fluidised-bed (BFB) gasifier, where the sorbent-to-biomass proportion, steam excess and gasification temperature were modified to determine their influence on process performance. More specifically, syngas yield and composition, solids conversion and tar formation during the gasification of this MSW feedstock were carefully analysed while modifying such operating conditions. Understanding the variation in such variables with the main operating conditions will be crucial for calculating the performance of an industrial plant based on this promising gasification technology and, therefore, advancing the scaling-up of this novel valorisation route.

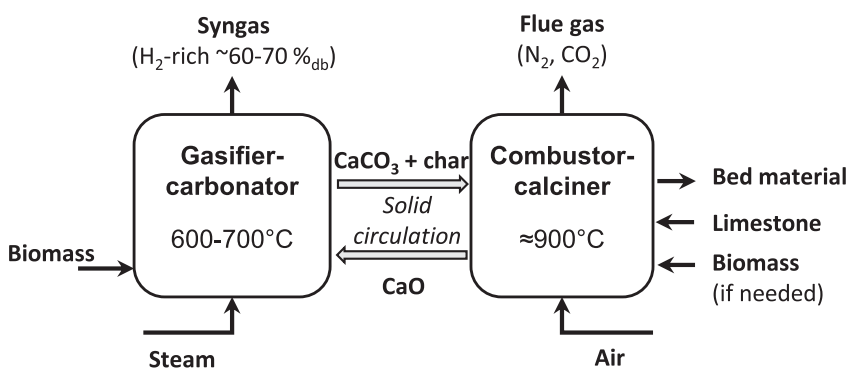

Fig. 1. Conceptual scheme of the Sorption-Enhanced Gasification (SEG) process. 


\section{Experimental}

\subsection{Feedstocks (biomass and $\mathrm{CO}_{2}$ sorbent) characterisation}

The MSW-derived material used as feedstock was provided by the Spanish company Econward, whose proprietary technology enables the recovery of the organic fraction from MSW through a thermal pressure hydrolysis system. The Econward technology consists of the thermal treatment of the MSW (which has previously undergone a separation process for the iron-based fraction) in an autoclave reactor using saturated steam at 5 bar to sterilise and homogenise the organic fraction. The smaller fraction of the treated material, which contains this organic fraction together with paper and cardboard, is then separated, dried and pelletised (20-26 mm in length and $6 \mathrm{~mm}$ in width) to facilitate its feeding into the BFB reactor. The ultimate and proximate analyses, and calorific value of the pelletised MSW derived material were determined, obtaining the results compiled in Table 1 . In order to determine the properties shown in this table, representative samples of this material were left to stabilise in air until constant weight was reached before being analysed. Ultimate analysis (carbon, hydrogen and nitrogen) was determined in a Thermo Flash 111 (UNE-EN ISO 16948:2015) where complete combustion of the sample occurs inside a high-temperature reactor followed by an accurate analysis of the flue gas. Moisture, volatile matter and ash contents were calculated according to UNE-EN ISO 18134:2016, UNE-EN 18123:2016 and UNE-EN ISO 18122:2016 standards, respectively. Lower heating value was calculated from the high heating value determined in an IKA C-2000 isoperibolic calorimeter (UNE-EN 14918:2011). Sulphur and chlorine contents were determined by ionic chromatography of the rinsing water used to clean the combustion flue gas using a Metrohm ion chromatograph with a conductivity detector (UNE-EN 15289). Finally, ash composition was also measured by inductively coupled plasma-optical emission spectrometry (ICP-OES) (UNE-EN 15290), obtaining the results shown in Table 2.

The $\mathrm{CO}_{2}$ sorbent used as bed material for the experiments was obtained by the calcination of limestone in the BFB reactor at around $910{ }^{\circ} \mathrm{C}$ by means of the combustion with air of a high heating value residue, whose $\mathrm{S}$ content was about $0.12 \mathrm{wt} \%$ [21]. The mean particle size of the calcined sorbent used for the SEG tests was $277 \mu \mathrm{m}$. The calcined material used as both the $\mathrm{CO}_{2}$ sorbent and the bed material was analysed with ICP-OES to determine its chemical composition, which is shown in Table 3 (each element expressed as the most probable metal oxide form). As shown in this table, the calcined material has a $\mathrm{CaO}$ content higher than 92 wt $\%$ with $\mathrm{Fe}_{2} \mathrm{O}_{3}$ and $\mathrm{MgO}$ as major impurities, with contents of $0.86 \mathrm{wt} \%$ and $0.85 \mathrm{wt} \%$ respectively. Moreover, the calcined material was also texturally characterised to determine its porosity, BET surface and solid density, which have been also included in Table 3. Pore volume was determined using a $\mathrm{Hg}$ Porosimeter Quantachrome Pore Master and solid density with a $\mathrm{He}$ pycnometer (Accupyc 1340 by Micromeritics). $\mathrm{N}_{2}$ adsorption (Micromeritics ASAP2020) at $77 \mathrm{~K}$ was used to calculate the sorbent surface area by applying the Brunauer - Emmett - Teller equation. Finally, the active $\mathrm{CaO}$ content of the sorbent introduced during the SEG tests was determined in an atmospheric thermogravimetric analyser (TGA) described elsewhere $[22,23]$. A $\mathrm{CaO}$ carbonation step was performed in the TGA using a gas mixture of $15 \mathrm{vol} \% \mathrm{CO}_{2}$ in $\mathrm{N}_{2}$ at $650{ }^{\circ} \mathrm{C}$ for $15 \mathrm{~min}$. The $\mathrm{CO}_{2}$ carrying capacity of the sorbent resulted in $0.35 \mathrm{~g} \mathrm{CO}_{2} / \mathrm{g}$ calcined material, which corresponds to $0.49 \mathrm{~mol}_{\mathrm{CO} 2} / \mathrm{mol}_{\mathrm{Ca}}$ expressed on a molar basis. This $\mathrm{CO}_{2}$ carrying capacity value was well below the value of $0.55 \mathrm{~g} \mathrm{CO}_{2} / \mathrm{g}$ calcined material determined when calcining the parent limestone in the TGA under controlled conditions (i.e. at $900{ }^{\circ} \mathrm{C}$ in air for $5 \mathrm{~min}$ ). Different reasons can cause this drastic decay in the $\mathrm{CO}_{2}$ carrying capacity of the sorbent after being calcined in the reactor, mainly linked to sintering phenomena and/or the presence of sulphur in the sorbent in the form of $\mathrm{CaSO}_{4}$ with a higher molar volume than that of $\mathrm{CaCO}_{3}$ [24]. Considering that all the sulphur determined by ICP-OES in the calcined material was in the form of $\mathrm{CaSO}_{4}$, this compound would represent $0.25 \mathrm{wt} \%$ as indicated in Table 3.

\section{2. $30 \mathrm{~kW}_{\text {th }}$ bubbling fluidised-bed (BFB) facility}

SEG tests were carried out in a $30 \mathrm{~kW}_{\text {th }}$ (referring to the nominal thermal input of biomass in LHV-basis) bubbling fluidised-bed reactor (BFBR) plant located at ICB-CSIC, which has been already described by Martínez et al. [21]. The reactor is a stainless steel vessel standing $3 \mathrm{~m}$ in height and comprising a dense bottom zone with an internal diameter of $0.15 \mathrm{~m}$. The reactor is externally heated by three electrical resistance elements and insulated with glass wool as shown in the schematic diagram of the plant in Fig. 2. $\mathrm{CO}_{2}$ sorbent and biomass are fed separately into the reactor from two independent closed hoppers by means of two screw feeders that introduce the solids into the bottom of the reactor. The biomass screw feeder is externally cooled with water in order to prevent its excessive heating due to conduction and therefore the prompt decomposition of the biomass in the screw. The $\mathrm{CO}_{2}$ sorbent screw feeder is heat-traced up to $400{ }^{\circ} \mathrm{C}$ and insulated with glass wool. Partially converted solids are pulled out from the reactor through a lateral overflow (indicated schematically on the left-hand side of the reactor in Fig. 2), and collected in a hopper that is periodically discharged during operation. This solid stream consists of unconverted biomass char and partially carbonated $\mathrm{CaO}$ particles. The overflow regulates solid bed inventory in the dense bottom zone of the reactor, resulting in around 5-7 kg, depending on fluidisation conditions.

$\mathrm{N}_{2}$ at a flow rate of $0.009 \mathrm{Nm}^{3} / \mathrm{min}$ was fed in with the $\mathrm{H}_{2} \mathrm{O}$ to facilitate its flow through the evaporation system. At the evaporator outlet, inside the reactor inlet gas pipe, the $\mathrm{H}_{2} \mathrm{O} / \mathrm{N}_{2}$ mixture was at a temperature of $120{ }^{\circ} \mathrm{C}-140{ }^{\circ} \mathrm{C}$. Moreover, $\mathrm{N}_{2}$ at a flow rate of 0.003 $\mathrm{Nm}^{3} /$ min was also fed into the reactor through the $\mathrm{CO}_{2}$ sorbent screw feeder, the overflow solids hopper and the biomass hopper to avoid a backflow of $\mathrm{H}_{2} \mathrm{O}$-rich syngas, which would have caused operational problems. Both $\mathrm{N}_{2}$ flow rates accounted for between $27 \mathrm{vol} \%$ and $37 \mathrm{vol}$ $\%$ (dry basis) of the product gas composition and served as an internal standard with which to calculate the syngas flow rate at the gasifier outlet by solving the $\mathrm{N}$ balance to the BFBR. Two high efficiency cyclones separated entrained particles of $\mathrm{CO}_{2}$ sorbent and unconverted char generated during the gasification process. The syngas was then cooled down to around $35^{\circ} \mathrm{C}$ in a shell-and-tube condenser using water as a coolant before passing through a commercial filter to be burnt in a flare and sent into the atmosphere.

The concentration of permanent gases (i.e. $\mathrm{H}_{2}, \mathrm{CH}_{4}, \mathrm{CO}$ and $\mathrm{CO}_{2}$, initially) during plant operation was measured online using a SICK GMS810 analyser placed downstream from the filter or downstream from the tar sampling system, as depicted in Fig. 2. Moreover, Tedlar sampling bags were used to take gas samples during steady-state operation for off-line analysis by gas chromatography to determine gas composition for permanent gases and light hydrocarbons (up to $\mathrm{C}_{4}$ ). A Varian CP-3800 gas chromatograph (GC) was used equipped with both a TCD and a FID detector. Separation was performed by using three SS packed columns (Molsieve 13X, HayeSep Q and HayeSep T) and a wide bore capillary column ( $\mathrm{HP} \mathrm{Al} / \mathrm{KCl})$. The permanent gases analysed at

\section{Table 1}

Ultimate and proximate analyses as well as calorific value of the MSW-derived biomass used as feedstock for SEG tests.

\begin{tabular}{lcll}
\hline \multicolumn{2}{l}{ Ultimate analysis [wt\%, dry-ash free basis]* } & \multicolumn{2}{l}{ Proximate analysis $[\mathrm{wt} \%]^{*}$} \\
\hline $\mathrm{C}$ & 34.80 & Moisture & 5.90 \\
$\mathrm{H}$ & 4.40 & Volatile matter & 55.40 \\
$\mathrm{~N}$ & 1.70 & Ash & 32.20 \\
$\mathrm{~S}$ & 0.43 & Fixed carbon & 6.60 \\
$\mathrm{O}$ & 30.9 & LHV $[\mathrm{MJ} / \mathrm{kg}]^{*}$ & 12.84 \\
$\mathrm{Cl}$ & 0.66 &
\end{tabular}

*Referred to the weight of the samples after stabilisation in air until constant weight. 
Table 2

Ash chemical composition (expressed as weight percentage in the ashes) of the MSWderived biomass used as feedstock for SEG tests.

\begin{tabular}{ll}
\hline & wt $\%$ in ashes \\
\hline $\mathrm{Al}$ & 2.39 \\
$\mathrm{Ca}$ & 21.2 \\
$\mathrm{Fe}$ & 1.31 \\
$\mathrm{~K}$ & 4.43 \\
$\mathrm{Mg}$ & 2.25 \\
$\mathrm{Mn}$ & 0.09 \\
$\mathrm{Na}$ & 2.78 \\
$\mathrm{P}$ & 1.22 \\
$\mathrm{Si}$ & 15.5 \\
$\mathrm{Ti}$ & 0.25 \\
\hline
\end{tabular}

Table 3

Composition and textural characterisation of the calcined limestone used as $\mathrm{CO}_{2}$ sorbent for SEG tests.

\begin{tabular}{ll}
\hline Composition [wt\%] & \\
\hline $\mathrm{CaO}$ & 92.24 \\
$\mathrm{Al}_{2} \mathrm{O}_{3}$ & 0.41 \\
$\mathrm{Fe}_{2} \mathrm{O}_{3}$ & 0.86 \\
$\mathrm{~K}_{2} \mathrm{O}$ & 0.05 \\
$\mathrm{MgO}$ & 0.85 \\
$\mathrm{Na}$ & 0.11 \\
$\mathrm{SiO}_{2}$ & 0.21 \\
$\mathrm{CaSO}_{4}$ & 0.25 \\
$\mathrm{Textural}$ characterisation & \\
Porosity $[-]$ & 0.42 \\
Surface area $\left[\mathrm{m}^{2} / \mathrm{g}\right]$ & 11.6 \\
Solid density $\left[\mathrm{kg} / \mathrm{m}^{3}\right]$ & 3202 \\
\hline
\end{tabular}

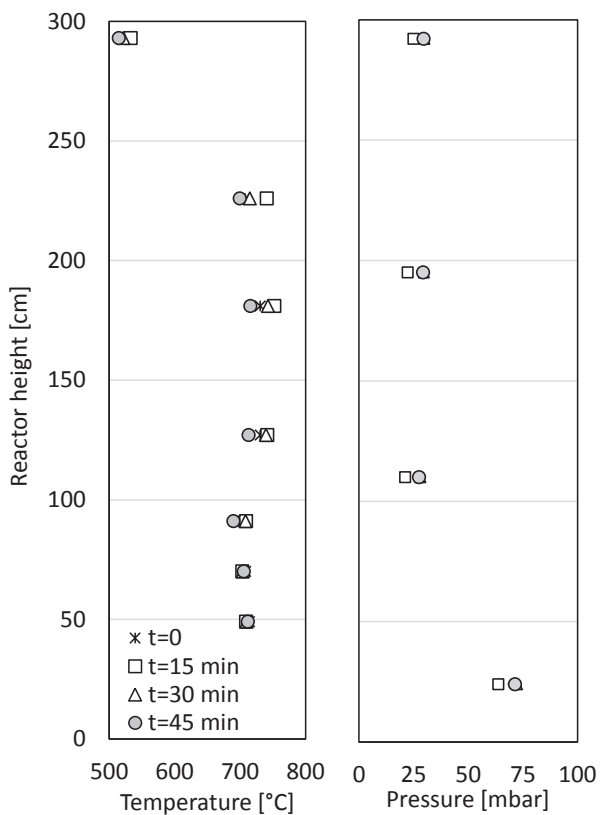

Fig. 3. Temperature and pressure profiles along the reactor during SEG experiment No. 7 in Table 4.

this stage were $\mathrm{H}_{2}, \mathrm{CO}_{2}$ and $\mathrm{CO}$, in addition to $\mathrm{O}_{2}$ and $\mathrm{N}_{2}$. The light hydrocarbons analysed were methane, ethane, ethylene, propane, propylene, isobutane, n-butane, trans-2-butene, 1-butene, isobutene, cis-2-butene and 1,3-butadiene.

The experimental routine followed in each experiment has been already detailed elsewhere [21]. The steady-state period was kept for one hour, and solid/gas samples were taken every $15 \mathrm{~min}$ from the overflow, cyclones and the gas line connected to the online analyser. Values of temperature, pressure, gas concentrations, fuel, sorbent and
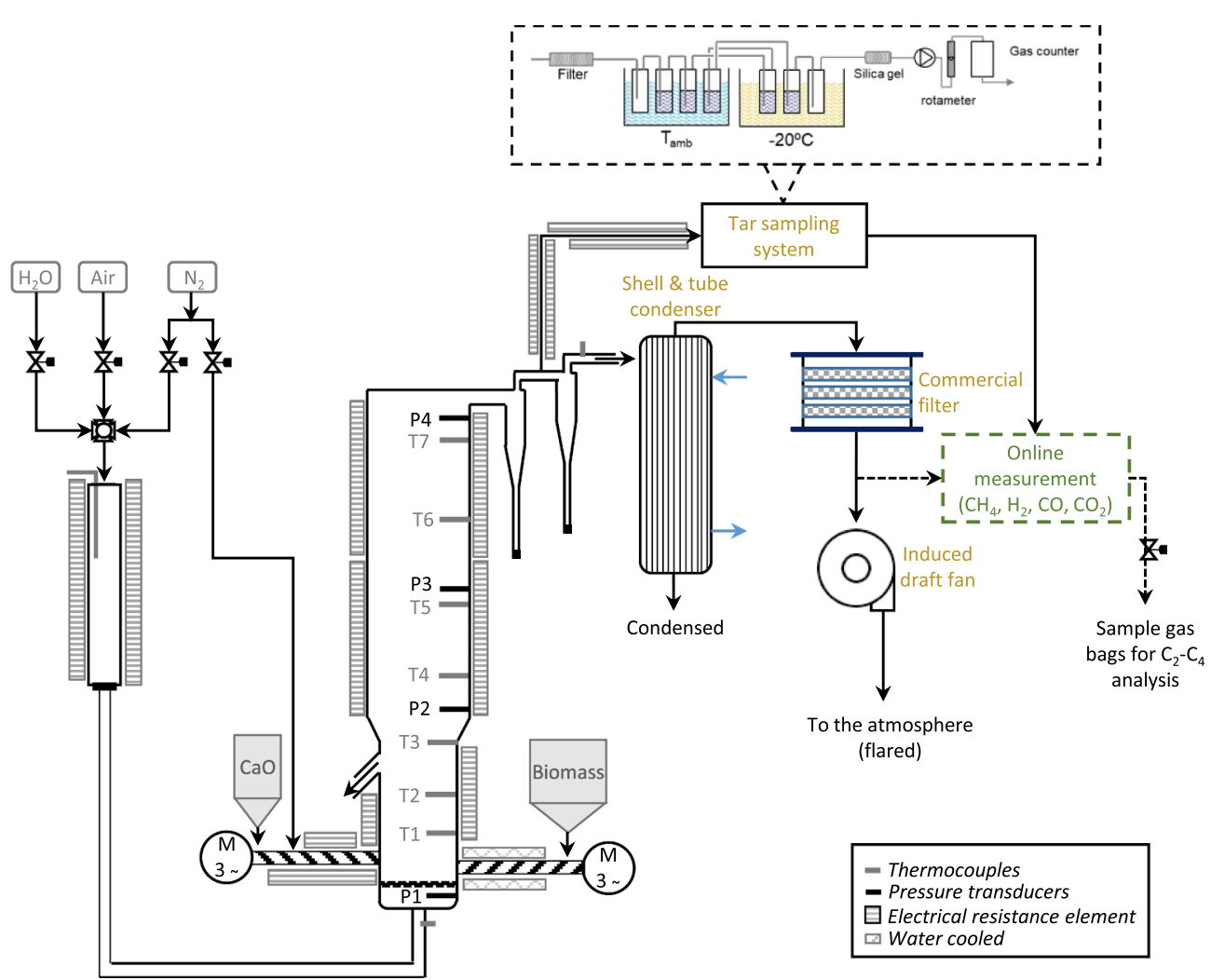

Fig. 2. Scheme of the $30 \mathrm{~kW}_{\text {th }}$ bubbling fluidised bed (BFB) gasification plant at ICB-CSIC. 
steam flow rates were continuously recorded during the course of the experiments, and mean values were calculated during representative periods of $15 \mathrm{~min}$ throughout the steady-state period. Pressure and temperature profiles were measured in the reactor by several thermocouples and pressure transducers placed along the reactor height as indicated in Fig. 2. Fig. 3 shows an example of these profiles for a specific experiment at different times during the steady-state period. As noticed, the solid bed temperature measured by thermocouples 1 and 2 remained quite stable during the steady-state period, with variations of $<5{ }^{\circ} \mathrm{C}$ owing to the vigorous fluidisation conditions used for the experiments $\left(\mathrm{u}_{0} / \mathrm{u}_{\mathrm{mf}} \sim 4-5\right)$. These fluidisation conditions allowed the segregation of the unconverted char pellets to be reduced, according to Aznar et al. [25]. Freeboard temperatures showed slightly higher variations of $30{ }^{\circ} \mathrm{C}-40{ }^{\circ} \mathrm{C}$ during such steady-state periods, and were adjusted to be similar to those in the dense solid bed thanks to the electrical resistance elements placed along the reactor height, which was important for evaluating the effect of this variable on product gas yield and composition. The temperature in the final part of the reactor, close to the exit pipe before the cyclone, decreased noticeably by about $170{ }^{\circ} \mathrm{C}$ with respect to the average reactor temperature due to heat losses at this location. This lower temperature zone could favour the carbonation of the entrained particles collected in the cyclones that could affect the composition of the syngas (i.e. decreasing the $\mathrm{CO}_{2}$ content). However, the amount of elutriated particles was quite low, representing between $1 \%$ and $4 \%$ of the total solids collected through the overflow in all the experiments, which constituted a solid-to-gas ratio in the exit pipe of the gasifier between $10 \mathrm{~g}$ and $40 \mathrm{~g}$ of solids per $\mathrm{kg}$ of syngas. Considering the variation in the carbonation degree of the sorbent particles collected in the cyclones with respect to those collected through the overflow, both calculated as explained in section 2.4, the carbonation of the entrained solids in such a low temperature region could lead to the $\mathrm{CO}_{2}$ concentration measured at the reactor outlet varying by $<0.04$ percentage points.

Table 4 summarises the experiments carried out in the $30 \mathrm{~kW}_{\text {th }}$ gasifier shown in Fig. 2. The studied operating parameters were the steam excess introduced into the gasifier (measured through the molar steam-to-carbon ratio that refers to the moles of steam used as gasifying agent per mole of $\mathrm{C}$ in the biomass), the sorbent-to-biomass ratio used (in weight basis) and the biomass thermal input, which resulted in different temperatures. Mean solid bed temperature reached during the experiment, mean solids residence time and fixed carbon conversion (both calculated as detailed below) have been included in this table.

\subsection{Tar sampling characterisation and quantitative analysis}

An off-line method for tar sampling was used based on the specific protocol for biomass gasification units described by Neeft [26]. This tar sampling method is based on the absorption of tars by flowing the gas through a series of 7 impinger bottles filled with isopropanol, which are placed in two different cooling baths as shown in detail in Fig. 2: four impingers (1, 2, 3 and 5) at room temperature, and three (4, 6 and 7) at $-20{ }^{\circ} \mathrm{C}$. All of them contained $100 \mathrm{ml}$ of isopropanol, with the exception of impingers 1 and 7, which were empty. The gas flow rate sampled through the tar system was regulated by a pump and the total volume passed was measured by a gas-meter before sending the gas to the online analyser. Tar sampling was performed for $30 \mathrm{~min}$ in all the gasification experiments, with between 501 and 1001 of dry gas passing through the sampling system.

After the experiment, the isopropanol from the seven impingers was mixed thoroughly in an amber glass bottle, and the impingers and connection tubes were rinsed with isopropanol. About 0.7-0.8 1 of isopropanol (containing tar and water) were usually obtained. The water content of the solution was determined using the Karl-Fischer titration method (CRISON TitroMatic $1 \mathrm{~S} \mathrm{kF}$ apparatus). The quantitative determination of the different tar compounds in the isopropanol solution was determined by a Varian CP-3800 gas chromatograph connected to a Saturn 2200 Ion Trap Mass Spectrometer (GC-MS). The GC-MS was operated in electron ionisation mode within the 35-550 m/ $z$ range. The identification and quantification of compounds were performed by external standard calibration for a total of 22 compounds according to the quantitation ion. The list of quantified compounds include lighter compounds such as benzene, toluene and xylene, as detailed in section 3.3.

Moreover, gravimetric tar was also determined for each experiment. An aliquot of $100 \mathrm{ml}$ of the collected tar solution was concentrated by rotary evaporator until dryness at controlled temperature and vacuum. The sample was then kept in a desiccator for at least $12 \mathrm{~h}$ and weighed on a microbalance with a precision of $0.1 \mathrm{mg}$. The gravimetric tar corresponded to the solid residue obtained in this concentration process and was expressed according to the gas volume that had passed through the sampling system as $\mathrm{g} / \mathrm{Nm}^{3}$ of dry gas.

\subsection{Solid samples characterisation}

Solid samples were taken every 15 min over one hour of steady-state operation from the solids collected through the overflow and from the elutriated material separated in the cyclones. Material separated in the cyclones consisted mainly of carbonated $\mathrm{CO}_{2}$ sorbent lost by attrition and biomass ashes with small contents of unconverted fixed carbon. Solids exiting the BFBR through the overflow consisted of a mixture of coarse particles (i.e. $>2 \mathrm{~mm}$ ) that corresponded to unconverted biomass pellets and smaller particles (i.e. $<2 \mathrm{~mm}$ ) that consisted mainly of partially converted $\mathrm{CO}_{2}$ sorbent particles with small quantities of unconverted char. Overflow solids were sieved to separate coarse particles from smaller particles, and samples from each solid fraction were conveniently separated to be analysed as follows.

Unconverted biomass pellets (i.e. coarse particles $>2 \mathrm{~mm}$ ) were analysed to determine their ultimate and proximate analyses according to the procedures already indicated for the MSW derived biomass used as feedstock. Smaller particles $<2 \mathrm{~mm}$ containing partially converted $\mathrm{CO}_{2}$ sorbent particles and unconverted char as well as solids collected from the cyclones were characterised using the following techniques to determine their composition:

- X-ray diffraction (XRD) analysis was performed in a Bruker D8 Advance diffractometer to determine the nature of the crystalline phases as well as their relative amount. Using this technique, the presence of $\mathrm{KCl}$ was detected in the solid samples collected in the cyclones, which contained a relatively high amount of fly ash. The amount of ashes in the solids separated in the cyclones varied between around $8 \mathrm{wt} \%$ and $30-31 \mathrm{wt} \%$ for those experiments performed under high sorbent-to-biomass ratios. For those experiments with larger contents of fly ash in the cyclone solids, the $\mathrm{KCl}$ content in the sampled solids varied between $3 \mathrm{wt} \%$ and $7 \mathrm{wt} \%$. However, for those experiments where there were low amounts of fly ash, $\mathrm{KCl}$ was not detected by XRD. Moreover, the XRD pattern obtained

\section{Table 4}

Operating parameters used and solid bed temperature, solids residence time and fixed carbon conversion achieved for the SEG experiments performed in the $30 \mathrm{~kW}_{\text {th }}$ BFB gasifier.

\begin{tabular}{lllllll}
\hline No. & $\begin{array}{l}\text { Biomass } \\
\text { thermal input } \\
{\left[\mathrm{kW}_{\text {th }}\right]}\end{array}$ & $\mathrm{S} / \mathrm{C}[-]$ & $\begin{array}{l}\text { Sorbent-to- } \\
\text { biomass (S/B) } \\
\text { mass ratio }\end{array}$ & $\mathrm{T}_{\text {bed }}\left[{ }^{\circ} \mathrm{C}\right]$ & $\tau_{\mathrm{s}}[\mathrm{min}]$ & $\mathrm{X}_{\mathrm{FC}}[\%]$ \\
\hline 1 & 18.4 & 1.4 & 0.46 & 634 & 138 & 36 \\
2 & 8.4 & 1.4 & 0.49 & 665 & 237 & 62 \\
3 & 11.4 & 1.4 & 0.69 & 682 & 137 & 45 \\
4 & 11.3 & 1.4 & 0.61 & 700 & 110 & 63 \\
5 & 11.3 & 1.4 & 0.81 & 684 & 108 & 33 \\
6 & 11.7 & 1.4 & 0.89 & 631 & 128 & 21 \\
7 & 9.0 & 1.4 & 1.98 & 706 & 75 & 29 \\
8 & 8.7 & 1.0 & 1.81 & 709 & 78 & 18 \\
\hline
\end{tabular}


allowed elucidation of the presence of $\mathrm{CaS}$ in the overflow particles resulting from the secondary reaction between the $\mathrm{CaO}$ and the $\mathrm{H}_{2} \mathrm{~S}$ formed in the gas phase from the $\mathrm{S}$ present in the biomass.

- Thermogravimetric analysis (TGA) was performed to determine the content of $\mathrm{CaCO}_{3}$ and fixed carbon in the solid samples. The experimental routine consisted of a heating period in $\mathrm{N}_{2}$ with a heating rate of $30{ }^{\circ} \mathrm{C} / \mathrm{min}$ up to $850{ }^{\circ} \mathrm{C}$ for $40 \mathrm{~min}$, and a second period at $850{ }^{\circ} \mathrm{C}$ using air as the carrier gas. During the first period in $\mathrm{N}_{2}$, a small weight loss of up to around $400{ }^{\circ} \mathrm{C}$ was observed that corresponded to the dehydration of the $\mathrm{Ca}(\mathrm{OH})_{2}$ formed during solids handling and the release of volatiles present in the unconverted char particles. The main weight loss occurred when well exceeding $720{ }^{\circ} \mathrm{C}$, corresponding to $\mathrm{CaCO}_{3}$ calcination into $\mathrm{CaO}$. Finally, a third weight loss was observed when switching from $\mathrm{N}_{2}$ to air at $850{ }^{\circ} \mathrm{C}$ due to fixed carbon combustion. From this analysis, the fixed carbon content and the total $\mathrm{CaCO}_{3}$ content were determined. It is worth mentioning that the $\mathrm{CaCO}_{3}$ determined by this technique corresponded not only to the $\mathrm{CaCO}_{3}$ formed by the carbonation of the $\mathrm{CaO}$ sorbent particles but also to the $\mathrm{CaCO}_{3}$ present in the biomass ashes (which is the form of the Ca contained in the ashes, Table 2).

- ICP-OES was used to determine the sulphur content in the "sorbentrich" overflow solids ( $<2 \mathrm{~mm}$ ). Hence, this sulphur content allowed the CaS content in these solids to be calculated based on the calcium phases detected by XRD analysis.

- Scanning electron microscopy (SEM) coupled with energy dispersive X-ray spectroscopy (EDX) was used to determine the total amount of $\mathrm{Ca}$ in the solids. The information obtained by this technique was used to calculate the $\mathrm{CaO}$ content of the solids once the $\mathrm{CaCO}_{3}$ and CaS contents had been determined by TGA and ICP-OES as described previously.

Based on the information gathered from these techniques, the amount of unconverted char in the "sorbent-rich" stream of solids exiting the BFBR through the overflow was calculated in order to estimate fixed carbon conversion. This amount of unconverted char was calculated from the fixed carbon content obtained by TGA, assuming the unconverted char in this "sorbent-rich" stream to have the same proximate analysis (and therefore fixed carbon content) as the coarse char particles collected in the same period of time through the overflow.

The $\mathrm{CO}_{2}$ content of the sorbent particles introduced into the BFBR (i.e. the $\mathrm{CaCO}_{3}$ formed in the gasifier) also needed to be calculated from this solid characterisation information in order to determine the extent of the carbonation reaction in the gasifier for each experiment. As previously indicated, the biomass used contained a significant amount of calcium in its ashes, accounting for $21.2 \mathrm{wt} \%$ in the calcined residue (Table 2). To elucidate the form of calcium in the ashes, information from XRD analysis on the solids collected in the cyclones turned out to be crucial. XRD analysis of these solids revealed that the only silicon phase corresponded to $\mathrm{SiO}_{2}$, whereas the calcium phases were exclusively $\mathrm{CaO}, \mathrm{CaCO}_{3}$ and $\mathrm{Ca}(\mathrm{OH})_{2}$. On the other hand, during the steady-state period, the temperature reached in the gasifier was not as high as to promote the calcination of the $\mathrm{CaCO}_{3}$ contained in the biomass ash in the presence of the $\mathrm{CO}_{2}$ in the gasification environment. Based on these facts, it was reasonable to assume that the calcium present in the ashes would be in the form of $\mathrm{CaCO}_{3}$ and not in the form of calcium silicate, and that the $\mathrm{CaCO}_{3}$ in the ash would remain as is in the BFBR and be collected in this form with the solids. TGA showed that the total amount of $\mathrm{CaCO}_{3}$ in the "sorbent-rich" stream of solids could be determined in this way (i.e. $\mathrm{CaCO}_{3}$ from ash and from carbonation of $\mathrm{CaO}$ particles). Once the amount of unconverted char in these solids is determined, the amount of $\mathrm{CaCO}_{3}$ in the ashes can be calculated, and by calculating the difference, the $\mathrm{CaCO}_{3}$ corresponding to the carbonation of $\mathrm{CaO}$ particles can be found. Finally, the amount of unreacted $\mathrm{CaO}$ can be estimated by using the information from SEM-EDX on the total calcium in these samples.

\section{Results and discussion}

\subsection{Product gas yield and composition}

The effect of solid bed temperature on syngas composition and syngas yield was analysed by experiments performed under the same steam-to-carbon (S/C) conditions (from tests 1 to 7 in Table 4). Fig. 4 shows the influence of the gasifier solid bed temperature on syngas yield and composition for these experiments. It can be observed that the product gas yield rises with solid bed temperature from $0.35-0.38$ $\mathrm{Nm}^{3} / \mathrm{kg}$ at $630-634{ }^{\circ} \mathrm{C}$ to $0.58-0.62 \mathrm{Nm}^{3} / \mathrm{kg}$ at $700-706{ }^{\circ} \mathrm{C}$. Correspondingly, the product gas yield expressed per kg of dry and ash-free biomass increases from $0.57-0.61 \mathrm{Nm}^{3} / \mathrm{kg}$ at $630-634{ }^{\circ} \mathrm{C}$ to $0.95-1.0 \mathrm{Nm}^{3} / \mathrm{kg}$ at $700-706{ }^{\circ} \mathrm{C}$. This increase in the product gas yield with gasification temperature is explained by (i) increased gas production during the primary pyrolysis stage, (ii) steam cracking and reforming of heavier hydrocarbons and tars, and (iii) enhanced char gasification reactions [15,27]. Generally, the distribution of primary pyrolysis products (i.e. gas or volatiles, tars and solid products) is influenced by temperature, heating rate, particle size and the type of biomass used. Once this primary pyrolysis has occurred, cracking and reforming reactions as well as char gasification reactions take place. Char gasification (generally represented as $\mathrm{C}_{(\mathrm{s})} \rightarrow \mathrm{CO}, \mathrm{CO}_{2}, \mathrm{H}_{2}, \mathrm{CH}_{4}$ ) is influenced by such operating parameters as temperature, solids residence time and S/C ratio. For the experiments represented in Fig. 4, the same biomass, particle size and S/C ratio were used, which makes temperature the main influencing parameter on the primary pyrolysis,
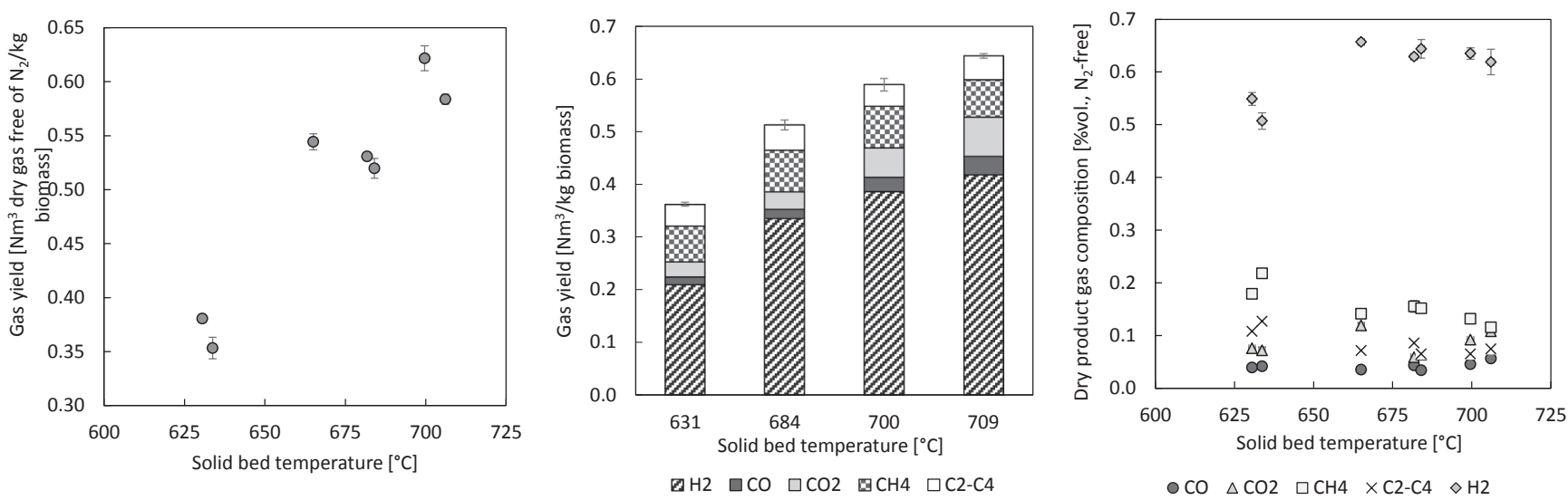

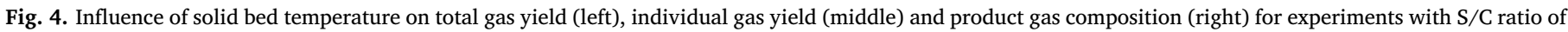

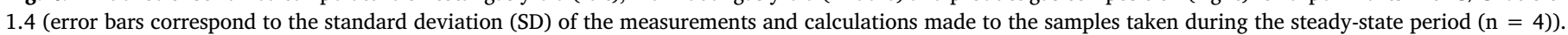


steam cracking, reforming and char gasification reactions occurring in the BFB gasifier. As can be appreciated from the experimental conditions shown in Table 4, the S/B ratio was also changed. This parameter mainly influences residence time of the particles in the gasifier, and ultimately char conversion and gas yield (see section 3.2 for more details). However, since the influence of the temperature on char conversion turned out to be more significant than the influence exerted by solids residence time, the analysis of the gas yield variation with the gasification temperature was preferred.

As seen in Fig. 4 (right), the concentration of $\mathrm{CH}_{4}$ and non-condensable hydrocarbons $\left(\mathrm{C}_{2}-\mathrm{C}_{4}\right)$ decreased with an increasing gasification temperature, confirming the enhancement of steam cracking and reforming reactions of these hydrocarbons into $\mathrm{CO}, \mathrm{CO}_{2}$ and $\mathrm{H}_{2}$ with increasing temperature. As regards char gasification, the carbon balance inside the BFB gasifier shows that about $30-32 \mathrm{~mol} \%$ of the carbon contained in the biomass can be found in the syngas produced when operating the gasifier at $630-634{ }^{\circ} \mathrm{C}$, whereas this proportion rises to $38-40 \mathrm{~mol} \%$ at $700-706{ }^{\circ} \mathrm{C}$. The remaining carbon can be found in the tars, unconverted char and $\mathrm{CaCO}_{3}$ formed, all of which leave the gasifier with either the gas product or the overflow solids. As discussed below in sections 3.2 and 3.3, both tar formation and carbon content in the unconverted char particles decreased with increasing temperature, confirming the higher content of carbon in the product gas as the gasification temperature increases. As can be seen in Fig. 4 (middle), the increase in the carbon content in the syngas product with the temperature is due to the higher $\mathrm{CO}_{2}$ and $\mathrm{CO}$ yields. The reduction in the carbonation extent of the $\mathrm{CaO}$ particles as the temperature increases and its impact on the extent of the WGS reaction are the main reasons for such increase in the $\mathrm{CO}_{2}$ and $\mathrm{CO}$ yields. However, as observed in Fig. 4 (middle), the variation of the $\mathrm{H}_{2}$ yield with the gasification temperature is the main factor contributing to the rise in the total gas yield.

Compared with the syngas composition obtained in a DFB system using non-catalytic bed materials such as silica sand and at a similar operating temperature in the gasifier [13], significantly higher $\mathrm{H}_{2}$ and lower $\mathrm{CO}$ and $\mathrm{CO}_{2}$ contents are achieved when using $\mathrm{CaO}$ as bed material in the gasifier, as already reported in many works in the literature $[12,14,28]$. The carbonation reaction of the $\mathrm{CaO}$ results in higher $\mathrm{H}_{2}$ contents in the syngas produced and lower $\mathrm{CO}$ contents due to the enhancement of the WGS reaction as $\mathrm{CO}_{2}$ is removed from the gas phase (equations (1) and (2)).

$\mathrm{CaO}+\mathrm{CO}_{2} \leftrightarrow \mathrm{CaCO}_{3}$

$\mathrm{CO}+\mathrm{H}_{2} \mathrm{O} \leftrightarrow \mathrm{CO}_{2}+\mathrm{H}_{2}$

However, differences can be observed when comparing the influence of gasifier temperature on the syngas $\mathrm{H}_{2}, \mathrm{CO}$ and $\mathrm{CO}_{2}$ contents shown in Fig. 4 (right) with that reported in the literature for DFB systems $[7,29,30]$. In SEG pilot plants with a DFB system, the $\mathrm{H}_{2}$ content in the syngas typically increases with decreasing gasifier
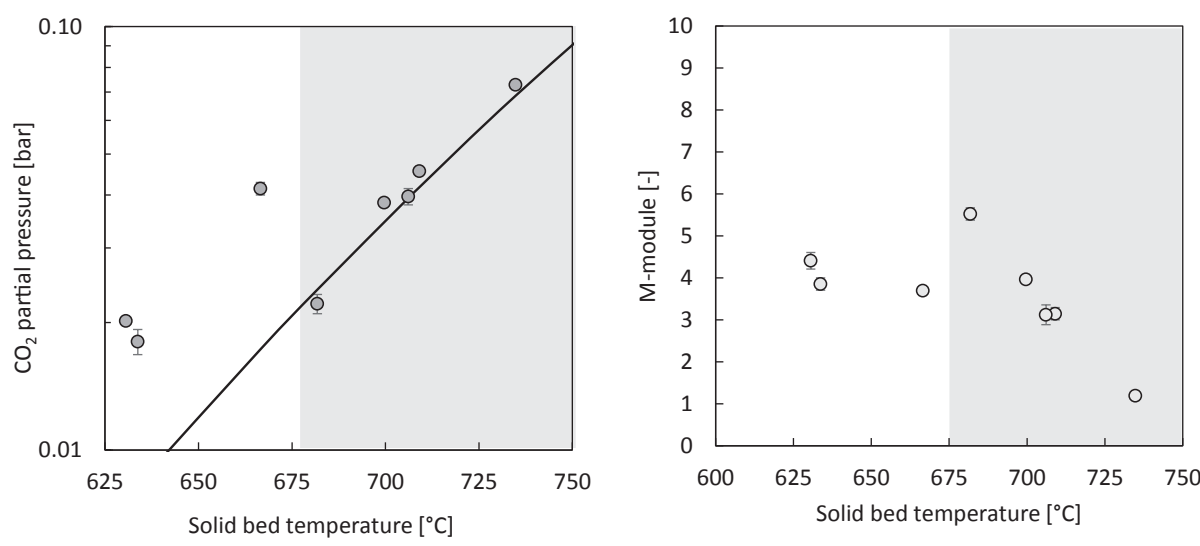

Fig. 5. $\mathrm{CO}_{2}$ partial pressure (left) and M-module (right) achieved in the syngas for different solid bed temperatures for runs $1-8$ in Table 4 (grey shaded area indicates those conditions controlled by the equilibrium of $\mathrm{CaO}$ carbonation). Error bars correspond to the SD of the measurements done to the gas samples taken during the steady-state period (n=4). 
conditions was reduced with increasing temperature. For temperatures below $680{ }^{\circ} \mathrm{C}$, the excess of $\mathrm{CO}_{2}$ in the gas phase that was unable to react with the $\mathrm{CaO}$ hindered the WGS reaction, preventing the consumption of $\mathrm{CO}$ through Equation (2). However, as the temperature increased and the $\mathrm{CO}_{2}$ content in the syngas became regulated through the carbonation equilibrium, the WGS was enhanced and the distance with equilibrium was reduced.

The behaviour of the $\mathrm{H}_{2}, \mathrm{CO}$ and $\mathrm{CO}_{2}$ contents in the syngas with gasification temperature explains the variation in the M-module reached (i.e. the $\left(\mathrm{H}_{2}-\mathrm{CO}_{2}\right) /\left(\mathrm{CO}+\mathrm{CO}_{2}\right)$ ratio) with temperature shown in Fig. 5 (right). The M-module reached its maximum of 6 at close to $680{ }^{\circ} \mathrm{C}$, decreasing from this value as the temperature rose. However, for lower temperatures, the high $\mathrm{CO}_{2}$ contents in the product gas made this M-module decrease, unlike what happens in SEG systems using a DFB [30]. The M-module allows monitoring of the suitability of the syngas produced for a given downstream synthesis process. For example, in case of synthetic biofuels like dimethyl-ether (DME), methanol or Fischer Tropsch, the desired H/C ratio or M-module is 2, whereas an M-module of 3 is preferred for methane production. Thus, according to Fig. 5 (right), the gasification of this MSW feedstock in the $\mathrm{BFB}$ reactor shown in Fig. 2 should occur at temperatures close to $720-725^{\circ} \mathrm{C}$ and under conditions of excess $\mathrm{CaO}$ in the reactor (i.e. high $\mathrm{S} / \mathrm{B}$ ratio) when aiming at M-modules of 2 in a downstream process. Also, this SEG plant should be operated under these conditions of high $\mathrm{CaO}$ excess in the reactor, but at temperatures close to $710{ }^{\circ} \mathrm{C}$ when a methanation process is located downstream. In this way, conditioning steps downstream the gasifier for adjusting $\mathrm{H}_{2}, \mathrm{CO}$ and $\mathrm{CO}_{2}$ contents would be avoided, which would simplify the process layout while preventing a negative impact on efficiency.

Finally, the effect of the steam excess used on the syngas composition was evaluated for experiments 7 and 8 in Table 4, performed under similar conditions of temperature and S/B ratio. Fig. 6 shows the syngas composition measured by GC for these experiments performed using different $\mathrm{S} / \mathrm{C}$ ratios. As observed, no significant influence of the steam excess used can be found in the composition of the syngas product. The $\mathrm{H}_{2}$ and $\mathrm{CO}$ contents were practically matched in both experiments, resulting in 64 and 5.4 vol\% (dry basis), respectively. Small differences in the $\mathrm{CO}_{2}$ content were found (i.e. $10.6 \mathrm{vol} \%$ and $11.4 \mathrm{vol} \%$ for S/C values of 1.3 and 1.0, respectively), but these are linked to the slightly different S/B ratios used in such experiments. The light hydrocarbon content slightly increased from 7 to $7.2 \mathrm{vol} \%$ when the steam excess was raised due to the enhancement of the reforming reactions with the increasing amount of steam. As a result, the M-module achieved was practically the same in both experiments. This behaviour in permanent gas composition with steam excess has been already observed in the literature for SEG technology performed in a DFB pilot plant [30]. However, an influence of steam excess on syngas composition has been reported for conventional steam gasification, especially on $\mathrm{CO}$ and $\mathrm{CO}_{2}$ contents, which are linked to the influence of this parameter on the WGS reaction (Eq. (2)) [15,33].

\subsection{Influence of operating parameters on char conversion}

The amount of unconverted char leaving the gasifier with the circulating solids in a SEG process is crucial for the energy balance in the combustor/calciner, influencing in this way the overall process efficiency. The energy released from its combustion in the combustor/ calciner determines whether or not an additional biomass supply is needed in this reactor to achieve the desired temperature of around $900{ }^{\circ} \mathrm{C}$ and sustain the endothermic calcination of the $\mathrm{CaCO}_{3}$ circulated from the gasifier. In the BFB reactor shown in Fig. 2, it is possible to determine both the amount and composition of the unconverted char particles leaving the gasifier through the overflow, facilitating the estimation of char conversion. Based on the proximate analysis of the unconverted pellets collected from the overflow shown in Table 5, biomass gasification was between devolatilisation and heterogeneous char gasification when partially converted pellets left the BFBR through the overflow. A more or less constant volatile content of between 12 and $14 \mathrm{wt} \%$ was determined in all the samples of unconverted pellets taken from the gasifier regardless of the operating conditions used during the experiment.

Based on the information gathered from the solid samples characterisation detailed in section 2.4, fixed carbon conversion $\left(\mathrm{X}_{\mathrm{FC}}\right)$ in the gasifier was calculated using Equation (3).

$X_{F C}=\left(1-\frac{m_{F C, O F,>2 m m}+m_{F C, O F,<2 m m}+m_{F C, c y c}}{m_{F C, b i o}}\right) \cdot 100$

where $\mathrm{m}_{\mathrm{FC}, \mathrm{OF}}>2 \mathrm{~mm}$ corresponds to the mass of fixed carbon contained in the coarse particles $(>2 \mathrm{~mm}$ ) collected through the overflow,

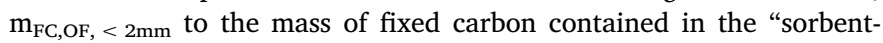
rich" solid fraction $(<2 \mathrm{~mm})$ from the overflow, $\mathrm{m}_{\mathrm{FC} \text {,cyc }}$ to the amount of fixed carbon separated in the cyclones, and $\mathrm{m}_{\mathrm{FC}}$, bio to the amount of fixed carbon introduced with the biomass during the same period of time (i.e. $15 \mathrm{~min}$ ) of the steady-state period.

The operating parameters influencing fixed carbon conversion in the gasifier correspond to the $\mathrm{S} / \mathrm{C}$ ratio, solid bed temperature and solids residence time. Char gasification reactions (Eqs. 4-7) are favoured by increasing the amount of steam introduced into the gasifier, the gasification temperature and/or the residence time of char particles in the reactor. The effect of the amount of steam introduced into the gasifier can be evaluated when comparing the results from experiments 7 and 8 in Table 4, which were performed under similar conditions of biomass thermal input, gasification temperature and S/B ratio. As confirmed from the results in this table, $\mathrm{X}_{\mathrm{FC}}$ increased from $18 \%$ to $29 \%$ by exclusively increasing the $\mathrm{S} / \mathrm{C}$ ratio from 1 to 1.4 . This is in agreement with the variation in the carbon content of the unconverted char pellets summarised in Table 5. For the experiment with an S/C ratio of 1 , char pellets had a carbon content of $0.256 \mathrm{~kg} / \mathrm{kg}$, whereas with an S/ $\mathrm{C}$ ratio of 1.4 this carbon content decreased to $0.223 \mathrm{~kg} / \mathrm{kg}$. However, the hydrogen content of the unconverted char pellets remained barely constant at $0.46-0.48 \mathrm{wt} \%$ regardless of the excess steam used. The variation in the carbon and hydrogen contents of the char particles with the $\mathrm{S} / \mathrm{C}$ ratio indicates that the steam excess influenced the conversion of the fixed carbon of the biomass, whereas the volatile fraction remained almost constant (around 12.5-12.6\% of volatile content in the unconverted char particles as shown in Table 5). Moreover, the sulphur present in the char should be linked to the carbon fraction since its content in char pellets changed from $0.6 \mathrm{wt} \%$ with an S/C of 1 to $0.5 \mathrm{wt}$ $\%$ when $\mathrm{S} / \mathrm{C}$ was raised to 1.4 , as it is released to the gas phase as char gasification occurs.

$\mathrm{C}_{(s)}+\mathrm{H}_{2} \mathrm{O} \leftrightarrow \mathrm{CO}+\mathrm{H}_{2}$

$\mathrm{C}_{(s)}+2 \mathrm{H}_{2} \mathrm{O} \leftrightarrow \mathrm{CO}_{2}+2 \mathrm{H}_{2}$

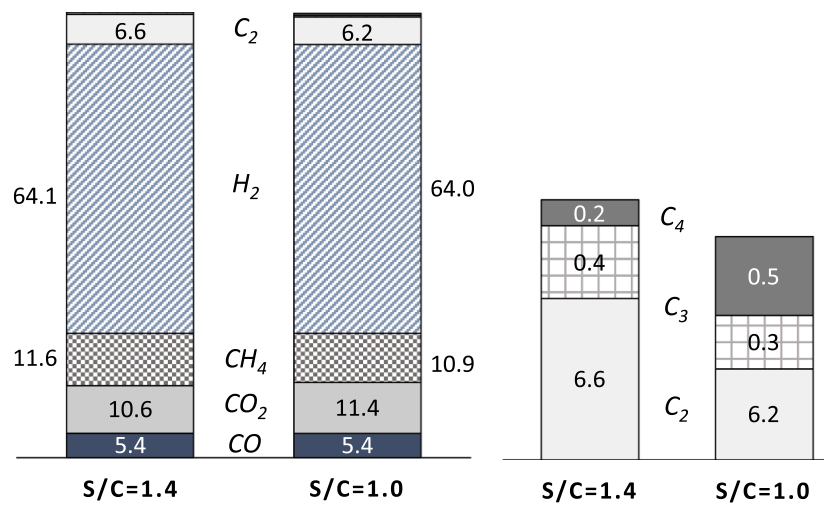

Fig. 6. Syngas composition for experiments 7 and 8 performed under different $\mathrm{S} / \mathrm{C}$ ratios. 
Table 5

Proximate and ultimate analyses of the unconverted char pellets collected in the experiments and $\mathrm{CaO}$ conversion calculated for the $\mathrm{CO}_{2}$ sorbent.

\begin{tabular}{|c|c|c|c|c|c|c|c|c|c|c|}
\hline \multirow[t]{2}{*}{ No. } & \multirow[t]{2}{*}{$\mathrm{S} / \mathrm{C}[-]$} & \multirow[t]{2}{*}{$\mathrm{T}_{\text {bed }}\left[{ }^{\circ} \mathrm{C}\right]$} & \multirow[t]{2}{*}{$\tau_{\mathrm{s}}[\mathrm{min}]$} & \multicolumn{3}{|c|}{ Unconverted char pellets, ultimate analysis ( $w \mathrm{t} \%$ ) } & \multicolumn{3}{|c|}{ Unconverted char pellets, proximate analysis (wt\%) } & \multirow[t]{2}{*}{$\mathrm{X}_{\mathrm{carb}}\left(\mathrm{mol}_{\mathrm{CO} 2} / \mathrm{mol}_{\mathrm{Ca}}\right)$} \\
\hline & & & & $\mathrm{C}$ & $\mathrm{H}$ & $\mathrm{S}$ & Moisture & Volatiles & FC & \\
\hline 1 & 1.4 & 634 & 138 & 26.7 & 0.68 & 0.6 & 2.5 & 16.4 & 11.7 & 0.53 \\
\hline 2 & 1.4 & 665 & 237 & 25.1 & 0.43 & 0.5 & 1.8 & 13.6 & 11.3 & 0.62 \\
\hline 3 & 1.4 & 682 & 137 & 27.4 & 0.50 & 0.5 & 1.0 & 13.4 & 11.5 & 0.38 \\
\hline 4 & 1.4 & 700 & 110 & 24.5 & 0.43 & 0.6 & 2.4 & 14.2 & 8.6 & 0.56 \\
\hline 5 & 1.4 & 684 & 108 & 25.9 & 0.50 & 0.6 & 2.2 & 13.8 & 24.4 & 0.48 \\
\hline 6 & 1.4 & 631 & 128 & 27.2 & 0.58 & 0.4 & 1.7 & 14.7 & 11.1 & 0.28 \\
\hline 7 & 1.4 & 706 & 75 & 22.3 & 0.48 & 0.5 & 1.2 & 12.5 & 20.5 & 0.19 \\
\hline 8 & 1.0 & 709 & 78 & 25.6 & 0.46 & 0.6 & 1.1 & 12.6 & 23.0 & 0.22 \\
\hline
\end{tabular}

$2 \mathrm{C}_{(s)}+2 \mathrm{H}_{2} \mathrm{O} \leftrightarrow \mathrm{CH}_{4}+\mathrm{CO}_{2}$

$\mathrm{C}_{(s)}+\mathrm{CO}_{2} \leftrightarrow 2 \mathrm{CO}$

With regard to the influence of gasification temperature and solids residence time on fixed carbon conversion, both operating parameters improve fixed carbon conversion when raised, as confirmed by the $\mathrm{X}_{\mathrm{FC}}$ values indicated in Table 4. The solids residence time in the BFB gasifier in Fig. 2 was considered to be governed by the residence time of the sorbent particles in the gasifier, and it was calculated according to equation (8) for each of the experiments indicated in Table 4.

$\tau_{s}=\frac{m_{C a}}{\dot{m}_{\text {sorbent }} \cdot y_{C a, s o r b}+\dot{m}_{b i o} \cdot y_{a s h, b i o} \cdot y_{C a, a s h}}$

In this expression, $\mathrm{m}_{\mathrm{Ca}}$ corresponds to the inventory of calcium in the dense bed of particles of the BFBR. For each experiment, $\mathrm{m}_{\mathrm{Ca}}$ was calculated using the total solids inventory (estimated through the pressure drop in the solid bed) and the fraction of calcium determined by SEM-EDX in the solid samples collected through the overflow. Moreover, $\mathrm{y}_{\mathrm{Ca}, \mathrm{i}}$ in Equation (8) indicates the mass fraction of calcium in the solid stream $i$ entering into the BFBR (i.e. either the calcined sorbent or the biomass).

To assess the effect of the solid bed temperature on char conversion, the experiments in Table 4 performed under similar conditions of S/C ratio and $\tau_{\mathrm{s}}$ should be compared. As can be observed in this table, $\mathrm{X}_{\mathrm{FC}}$ increased by 9 points when the gasification temperature rose from $634{ }^{\circ} \mathrm{C}$ to $682{ }^{\circ} \mathrm{C}$ (runs 1 and 3 in Table 4) and by 30 points when it increased from $684{ }^{\circ} \mathrm{C}$ to $700{ }^{\circ} \mathrm{C}$ (runs 4 and 5 in Table 4). Such behaviour indicates an exponential trend of fixed carbon conversion with the gasification temperature. The ultimate analyses of the unconverted char pellets in Table 5 show that the carbon content remained almost constant at $26.7-27.4 \mathrm{wt} \%$ in tests 1 and 3, but it decreased from $25.9 \%$

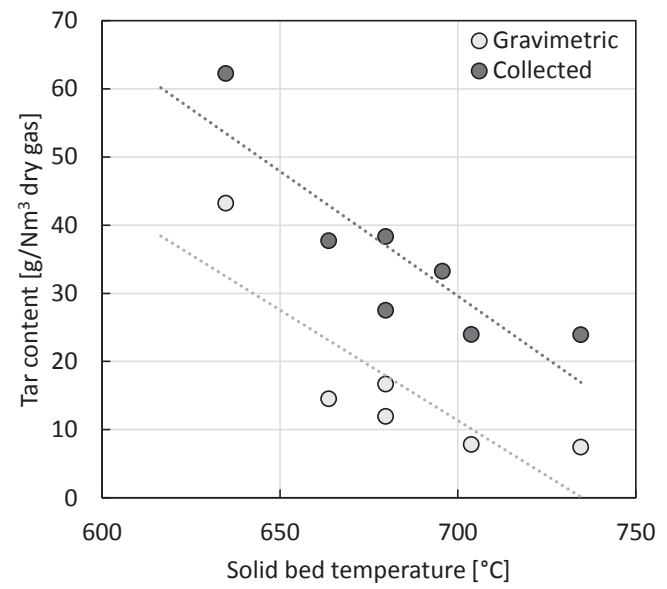

at $684{ }^{\circ} \mathrm{C}$ in run 5 to $24.5 \%$ as the temperature increased to $700{ }^{\circ} \mathrm{C}$ in run 4. Devolatilisation of biomass seems to be the main process occurring in the temperature range between $634{ }^{\circ} \mathrm{C}$ and $682{ }^{\circ} \mathrm{C}$, since the volatile content of unconverted char particles decreased from $16.4 \%$ at $634{ }^{\circ} \mathrm{C}$ to $13.4 \%$ at $682{ }^{\circ} \mathrm{C}$, while the fixed carbon content barely changed at $11.5-11.7 \%$. However, when the temperature rose to over $684^{\circ} \mathrm{C}$, char gasification (Eqs. (4)-(7)) gained importance, resulting in a reduction in the fixed carbon content in the unconverted char particles, as corroborated from results in Table 5 . The sole effect of $\tau_{\mathrm{s}}$ on char conversion can be evaluated by comparing the results from tests 3 and 5 in Table 4, which were performed under similar conditions of steam excess and gasification temperature. Under these conditions of $\mathrm{S} /$ $\mathrm{C}=1.4$ at $682-684{ }^{\circ} \mathrm{C}, \mathrm{X}_{\mathrm{FC}}$ increased from $33 \%$ to $45 \%$ when the $\mathrm{S} / \mathrm{B}$ ratio was decreased by extending the solids residence time in the BFBR by $30 \mathrm{~min}$.

Calculated $\mathrm{X}_{\mathrm{FC}}$ values for experiments performed under the same $\mathrm{S}$ / $\mathrm{C}$ ratio were correlated to solid bed temperature and $\tau_{\mathrm{s}}$ using the empirical model proposed by Pröll and Hofbauer [34] (Eq. (9)), where the empirical factor $\mathrm{k}(\mathrm{T})$ is considered a function of the temperature through the Arrhenius equation (10).

$X_{F C}=1-\frac{1}{1-k(T) \cdot \tau_{s}^{n}}$

$k=k_{0} \cdot e^{-E_{a} / R \cdot T}$

Using the $\mathrm{X}_{\mathrm{FC}}$ and $\tau_{\mathrm{s}}$ values calculated for the experiments under the same S/C ratio (runs 1-7 in Table 4), parameters $k_{0}, E_{a}$ and $n$ in the empirical model in Eq. (9) were regressed using multiple linear regression for this equation. The correlation of $\mathrm{X}_{\mathrm{FC}}$ with the solids residence time and the temperature proposed was investigated. Very low p-values for the independent variables $\tau_{\mathrm{s}}$ and solid bed temperature were obtained (i.e. 0.01 and 0.04 , respectively), meaning that both

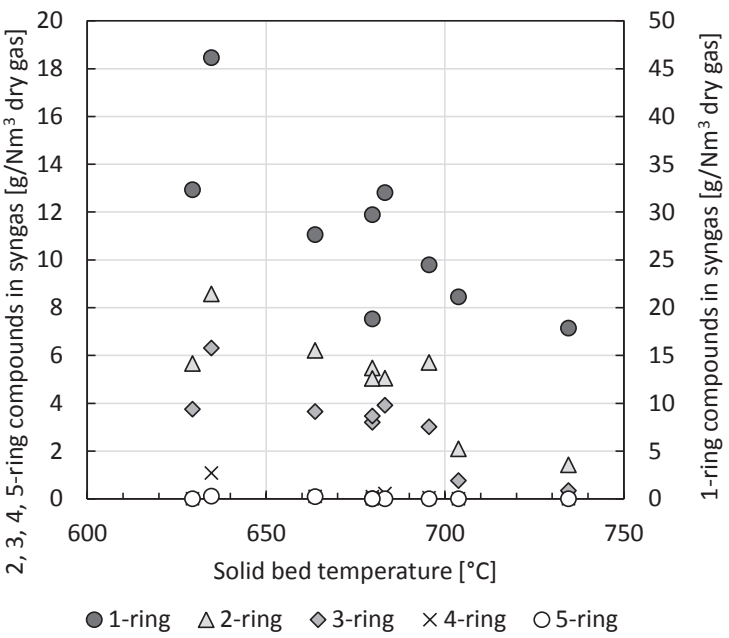

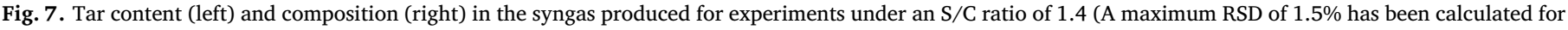
the gravimetric tar values $(n=3)$, whereas it ranges from lower than 1 to $10 \%$ for each individual compound analysed in the collected tar ( $=2)$ ). 
variables are statistically significant for correlating variations in $\mathrm{X}_{\mathrm{FC}}$. Calculated parameters from this regression analysis corresponded to $\mathrm{k}_{0}=38.7 \min ^{-1.7}, \mathrm{E}_{\mathrm{a}}=98.2 \mathrm{~kJ} / \mathrm{mol}$ and $\mathrm{n}=1.7$.

\subsection{Influence of operating parameters on tar formation and composition}

A very important issue related to biomass gasification is tar formation. Tar content and composition in the syngas product are important when designing the gas cleaning system needed since the presence of tars in the gas product may cause problems of fouling and soot formation in downstream processes. The type of biomass used and operating conditions in the gasifier, such as temperature, S/B ratio and $\mathrm{S} / \mathrm{C}$ ratio largely influence tar production and composition.

Fig. 7 shows the influence of solid bed temperature on tar content and composition in the syngas product obtained in the experiments performed with an S/C ratio of 1.4. The S/B ratio in these experiments correspond to those indicated in Table 4 . Results in this figure indicate a negative trend, with a decrease in both the collected and gravimetric (weight) tars with an increase in solid bed temperature. The gravimetric tar content in the product gas was found to decrease from $43 \mathrm{~g} / \mathrm{Nm}^{3}$ dry gas at $635{ }^{\circ} \mathrm{C}$ in the solid bed to barely $7 \mathrm{~g} / \mathrm{Nm}^{3}$ dry gas when the solid bed temperature increased above $700{ }^{\circ} \mathrm{C}$. This trend for tar content with gasification temperature has already been reported by other authors in the literature for large scale SEG systems using a DFB $[17,18]$. As temperature in the solid bed gasifier increases, tar formation from primary pyrolysis is reduced and thermal cracking and reforming reactions are favoured, with both factors contributing to reducing tar content in the syngas product. Many authors in the literature have already reported this trend for tar content with the temperature in SEG systems $[17,18,30]$. However, the gravimetric tar values measured in this work were higher than those found in the literature for SEG systems using a DFB facility, which usually resulted in between 8 and $31 \mathrm{~g} / \mathrm{Nm}^{3}$ (dry basis) at temperatures of $600-650{ }^{\circ} \mathrm{C}$ and $2-2.5 \mathrm{~g} / \mathrm{Nm}^{3}$ (dry basis) when increasing the gasifier temperature up to $700{ }^{\circ} \mathrm{C}[18,30,35]$. In this work, the gasifier was a BFB reactor with a very low presence of $\mathrm{CaO}$ in the freeboard region (i.e. $3 \mathrm{~g}$ and $10 \mathrm{~g}$ of $\mathrm{CaO}$ per $\mathrm{kg}$ of syngas), limiting the contact between the $\mathrm{CaO}$ and the gas product (and therefore the tars produced) and the dense solid bed. However, DFB systems usually work with larger S/B ratios at the gasifier inlet (i.e. (at least) 2.5-3.2 times higher than the highest S/B ratio achieved in this work, see Table 4) [18] and with higher solid-to-gas ratios throughout the freeboard region. Therefore, both factors contribute to an enhanced catalytic effect of the $\mathrm{CaO}$ on tar destruction compared to that produced in the BFB reactor used in this work [36].

The tar content calculated from the collected isopropanol solution (referred to as "collected") was found to be larger than the gravimetric tar content in every case, as observed in Fig. 7 (left). These differences are related to the nature of the identified compounds in each case. Whereas the most volatile compounds (i.e. hydrocarbons with one aromatic ring, such as benzene, toluene, (o,m, p-xylenes), and some polycyclic aromatic hydrocarbons, such as naphthalene) were the dominant hydrocarbons in the collected tar, the gravimetric tar mainly consisted of compounds such as naphthalene and other heavier hydrocarbons, whose concentration was higher than in the collected tar owing to the concentration process. As shown in Fig. 7 (right), 1-ring compounds were the major compounds found in the collected tar, accounting for between $18 \mathrm{~g} / \mathrm{Nm}^{3}$ of dry gas and $46 \mathrm{~g} / \mathrm{Nm}^{3}$ of dry gas at the highest $\left(734{ }^{\circ} \mathrm{C}\right)$ and the lowest $\left(635{ }^{\circ} \mathrm{C}\right)$ temperatures tested respectively, which represent as much as $78 \%$ of the total collected tar amount. These compounds were the ones being affected most by the temperature, and corresponded mainly to benzene, followed by toluene, phenol, $(p+m) x y l e n e$ and ethylbenzene, which was the minority 1-ring compound. Benzene was the major 1-ring compound quantified and its content varied between $13 \mathrm{~g} / \mathrm{Nm}^{3}$ dry gas and $29 \mathrm{~g} /$ $\mathrm{Nm}^{3}$ dry gas at the highest and the lowest temperatures aforementioned. The only 2-ring compound detected was naphthalene, while phenanthrene and acenapthylene were the main 3-ring compounds. These compounds (benzene, naphthalene and phenanthrene among others) are usually known as tertiary or recombination tars since they correspond to structures typically not found in natural biomass. At the low temperatures found in the SEG process, the possible formation mechanism leading to these compounds is the $2+4$ cycloaddition Diels-Alder mechanism [37]. As can be noticed in Fig. 7 (right), 4- and 5-ring compounds were not detected in the collected tar solution. However, when the gravimetric tar was being dissolved in $5 \mathrm{ml}$ of isopropanol for further injection into the GC-MS, the presence of 4-, 5and 6-ring compounds such as benzo(a)anthracene, chrysene, benzo(b) fluoranthene or indeno(1,2,3-cd)pyrene was detected.

The influence of the S/B ratio on tar formation can be evaluated by comparing experiments 4 and 7 in Table 4, which were run with the same steam excess $(\mathrm{S} / \mathrm{C}=1.4)$ and a similar solid bed temperature (700-706 ${ }^{\circ} \mathrm{C}$ ). Fig. 8 shows the tar content and composition for the collected tar obtained in these two experiments performed with radically different S/B ratios (i.e. 1.98 and $0.61 \mathrm{~kg}$ of sorbent $/ \mathrm{kg}$ biomass). As shown in this figure, the higher the $\mathrm{S} / \mathrm{B}$ ratio used in the gasifier, the lower the tar content in the syngas produced (both gravimetric and collected tar). Collected tar contents of $33.2 \mathrm{~g} / \mathrm{Nm}^{3}$ dry gas were calculated for experiment 4 , run with an S/B ratio of 0.61 , which decreased to $24.0 \mathrm{~g} / \mathrm{Nm}^{3}$ dry gas as the sorbent excess increased to $1.98 \mathrm{~kg}$ sorbent $/ \mathrm{kg}$ biomass. Gravimetric tar also decreased with the

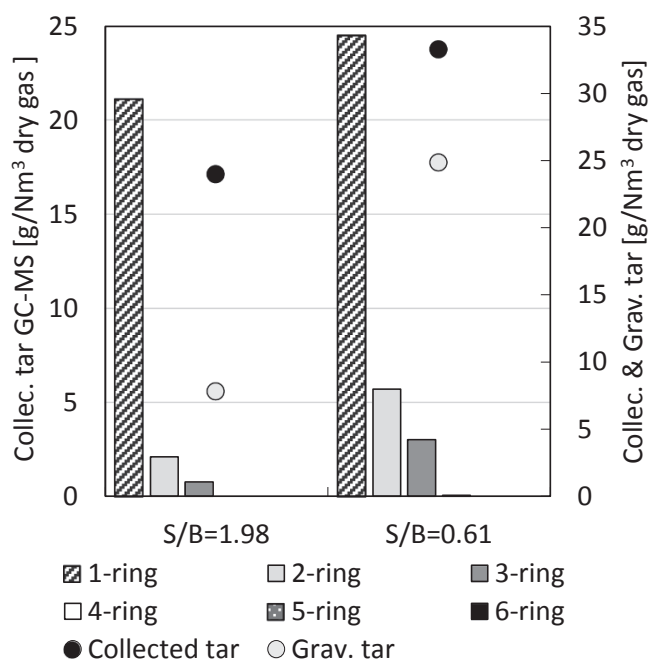

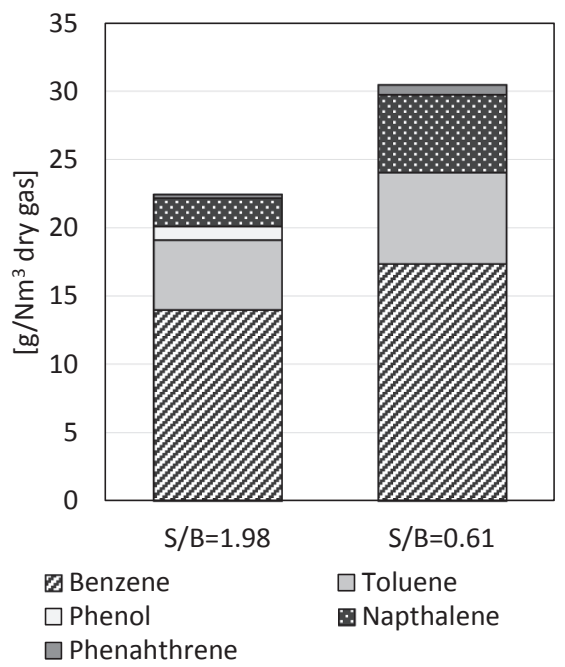

Fig. 8. (left) Collected tar and composition by compound and number of aromatic rings, and (right) major compounds in the collected tar for experiments 4 and 7, performed at similar solid bed temperature $\left(700-706{ }^{\circ} \mathrm{C}\right.$ ) and $\mathrm{S} / \mathrm{C}$ ratio (1.4), but different $\mathrm{S} / \mathrm{B}$ ratio (RSD ranges from lower than 1 to $10 \%$ for each individual compound analysed in the collected tar $(\mathrm{n}=2))$. 
increasing amount of sorbent used in the gasification, going from $24.8 \mathrm{~g} / \mathrm{Nm}^{3}$ dry gas to $7.8 \mathrm{~g} / \mathrm{Nm}^{3}$ dry gas. This behaviour is linked to the catalytic role of the $\mathrm{CaO}$ used as the $\mathrm{CO}_{2}$ sorbent in the cracking of the tars formed during gasification [28]. This catalytic activity of $\mathrm{CaO}$ is also corroborated from the composition of the main compounds in the collected tar. At higher S/B ratios, the formation of 4-6 ring compounds, the most dangerous polycyclic aromatic hydrocarbons (PAH) for human health, is completely avoided. Although it cannot be appreciated in Fig. 8 (left), 4-ring compounds (fluoranthene and pyrene) were detected in the collected tar for the experiment with an S/B of $0.61\left(0.05 \mathrm{~g} / \mathrm{Nm}^{3}\right.$ dry gas in total), although disappearing as the sorbent excess increased. With regard to the individual compounds (Fig. 8 right), benzene was the major compound emitted, and the rise in the sorbent excess used decreased the proportion of 2-ring compounds such as naphthalene and heavier compounds like phenanthrene. One exception was phenol, which was only emitted at the highest sorbent excess, as shown in Fig. 8 (right).

\section{Conclusions}

The gasification of an MSW-derived feedstock in the presence of $\mathrm{CaO}$ as bed material was studied in a $30 \mathrm{~kW}_{\text {th }} \mathrm{BFB}$ gasification plant. The operating parameters studied were the steam excess used, the S/B ratio introduced into the gasifier and the gasification temperature. The effect of such operating variables in the syngas yield and composition, solids conversion and tar formation was extensively assessed. Gasification temperature turned out to be the variable with the greatest influence on the $\mathrm{H}_{2}, \mathrm{CO}$ and $\mathrm{CO}_{2}$ contents of the syngas obtained, given the limiting mechanisms associated with the carbonation of the $\mathrm{CaO}$ used as bed material. At gasification temperatures higher than $680^{\circ} \mathrm{C}$, $\mathrm{CaO}$ carbonation limited the amount of $\mathrm{CO}_{2}$ that could be removed from the gas phase, which caused the $\mathrm{CO}_{2}$ content in the syngas to be regulated by the equilibrium of this gas-solid reaction. However, for temperatures below this limit, the availability of $\mathrm{CaO}$ that was able to react with the $\mathrm{CO}_{2}$ released from gasification reactions was found to be the limiting factor and the reason for the accumulation of $\mathrm{CO}_{2}$ in the gas product. The gasification temperature also influenced the conversion of the biomass, together with the solids residence time in the gasifier, resulting in a wide variation in fixed carbon conversion for the conditions studied. An empirical correlation between such variables and fixed carbon conversion was elucidated. Char gasification turned out to be the dominant process occurring in biomass conversion at temperatures above $680{ }^{\circ} \mathrm{C}$, whereas devolatilisation of biomass was the main reaction step occurring below this temperature.

Finally, tar yield and composition were determined for the experiments performed. Tar content was found to be mainly influenced by the gasification temperature and the S/B ratio used, with both factors contributing to a decrease in tar production when raised as the result of cracking reactions. This decrease was more remarkable in the gravimetric tar than in the collected tar. Gravimetric tar contents as high as $43 \mathrm{~g} / \mathrm{Nm}^{3}$ were calculated for gasification temperatures as low as $635{ }^{\circ} \mathrm{C}$, but this tar yield was reduced to barely $7 \mathrm{~g} / \mathrm{Nm}^{3}$ when the temperature increased up to $710{ }^{\circ} \mathrm{C}$. The tar composition consisted basically of 1-ring aromatic compounds (mainly benzene and toluene), which represented around $80 \%$ of the compounds determined by GC-MS analysis of the collected tar solution, whereas heavier aromatic compounds (compounds with 3 or more aromatic rings) represented $<3-4 \%$. The gravimetric tar values measured in this work were higher than those found in the literature for SEG systems using DFB facilities due to the limited presence of $\mathrm{CaO}$ in the freeboard region of the semi-batch BFB pilot plant used. However, if the BFB gasifier in this work were to be operated in dual mode connected to a combustor/ calciner, lower tar contents would be expected owing to the higher S/B ratios associated with such dual-bed operation.

\section{Declaration of Competing Interest}

The authors declare that they have no known competing financial interests or personal relationships that could have appeared to influence the work reported in this paper.

\section{Acknowledgements}

This work has been supported by the European Commission (FLEDGED project, grant agreement No. 727600); the Spanish Ministry of Science and Innovation, the State Research Agency and the European Founds for Regional Development (No. RTI2018-095575-B-I00, MCI/ AEI/FEDER, UE); and the Regional Aragon Government (DGA).

\section{References}

[1] Eurostat, Municipal waste statistics, (n.d.). https://ec.europa.eu/eurostat/statisticsexplained/index.php/Municipal_waste_statistics\#Municipal_waste_treatment (accessed February 25, 2020).

[2] G. Iaquaniello, G. Centi, A. Salladini, E. Palo, S. Perathoner, Waste to chemicals for a circular economy, Chem. - A Eur. J. 24 (2018) 11831-11839, https://doi.org/10. 1002/chem.201802903.

[3] M. Materazzi, A. Holt, Experimental analysis and preliminary assessment of an integrated thermochemical process for production of low-molecular weight biofuels from municipal solid waste (MSW), Renew. Energy 143 (2019) 663-678, https:// doi.org/10.1016/j.renene.2019.05.027.

[4] R. Rauch, J. Hrbek, H. Hofbauer, Biomass gasification for synthesis gas production and applications of the syngas, Wiley Interdiscip. Rev. Energy Environ. 3 (2014) 343-362, https://doi.org/10.1002/wene.97.

[5] K. Göransson, U. Söderlind, J. He, W. Zhang, Review of syngas production via biomass DFBGs, Renew. Sustain. Energy Rev. 15 (2011) 482-492, https://doi.org/ 10.1016/j.rser.2010.09.032.

[6] C. Aichernig, H. Hofbauer, R. Rauch, R. Koch, Biomass gasification CHP plant Güssing (Austria): Research centre for 2nd generation biofuels, in: 8th World Congr. Chem. Eng. Inc. 59th Can. Chem. Eng. Conf. 24th Interam. Congr. Chem. Eng., 2009.

[7] S. Koppatz, C. Pfeifer, R. Rauch, H. Hofbauer, T. Marquard-Moellenstedt, M. Specht, $\mathrm{H} 2$ rich product gas by steam gasification of biomass with in situ $\mathrm{CO} 2$ absorption in a dual fluidized bed system of 8 MW fuel input, Fuel Process. Technol. 90 (2009) 914-921, https://doi.org/10.1016/J.FUPROC.2009.03.016.

[8] H. Thunman, M. Seemann, T. Berdugo Vilches, J. Maric, D. Pallares, H. Ström, G. Berndes, P. Knutsson, A. Larsson, C. Breitholtz, O. Santos, Advanced biofuel production via gasification - lessons learned from 200 man-years of research activity with Chalmers' research gasifier and the GoBiGas demonstration plant, Energy Sci. Eng. 6 (2018) 6-34, https://doi.org/10.1002/ese3.188.

[9] A. Larsson, M. Seemann, D. Neves, H. Thunman, Evaluation of performance of industrial-scale dual fluidized bed gasifiers using the chalmers 2-4-MWth gasifier, Energy Fuels 27 (2013) 6665-6680, https://doi.org/10.1021/ef400981j.

[10] J. Kotik, R. Rauch, H. Hofbauer, K. Bosch, F. Schwenninger, 8.5 MWth CHP plant in oberwart, Austria - based on DFB Steam Gasification of Solid Biomass - Achieves Continuous Full Load Operation Through Stringent Optimization, 20th Eur. Biomass Conf. Exhib. (2012) 1033-1037.

[11] S. Heidenreich, M. Müller, P.U. Foscolo, Advanced biomass gasification. New concepts for efficiency increase and product flexibility, Elsevier, 2016.

[12] C. Pfeifer, S. Koppatz, H. Hofbauer, Steam gasification of various feedstocks at a dual fluidised bed gasifier: impacts of operation conditions and bed materials, Biomass Convers. Biorefinery 1 (2011) 39-53, https://doi.org/10.1007/s13399011-0007-1.

[13] D. Schweitzer, A. Gredinger, M. Schmid, G. Waizmann, M. Beirow, R. Spörl, G. Scheffknecht, Steam gasification of wood pellets, sewage sludge and manure: gasification performance and concentration of impurities, Biomass Bioenergy 111 (2018) 308-319, https://doi.org/10.1016/j.biombioe.2017.02.002.

[14] G. Soukup, C. Pfeifer, A. Kreuzeder, H. Hofbauer, In situ CO2 capture in a dual fluidized bed biomass steam gasifier - bed material and fuel variation, Chem. Eng. Technol. 32 (2009) 348-354, https://doi.org/10.1002/ceat.200800559.

[15] N.H. Florin, A.T. Harris, Enhanced hydrogen production from biomass with in situ carbon dioxide capture using calcium oxide sorbents, Chem. Eng. Sci. 63 (2008) 287-316, https://doi.org/10.1016/j.ces.2007.09.011.

[16] S. Heidenreich, P.U. Foscolo, New concepts in biomass gasification, Prog. Energy Combust. Sci. 46 (2015) 72-95, https://doi.org/10.1016/j.pecs.2014.06.002.

[17] J. Fuchs, J.C. Schmid, S. Müller, H. Hofbauer, Dual fluidized bed gasification of biomass with selective carbon dioxide removal and limestone as bed material: a review, Renew. Sustain. Energy Rev. 107 (2019) 212-231, https://doi.org/10. 1016/j.rser.2019.03.013.

[18] C. Hawthorne, N. Poboss, H. Dieter, A. Gredinger, M. Zieba, G. Scheffknecht, Operation and results of a 200-kWth dual fluidized bed pilot plant gasifier with adsorption-enhanced reforming, Biomass Convers. Biorefinery 2 (2012) 217-227, https://doi.org/10.1007/s13399-012-0053-3.

[19] J. Fuchs, S. Müller, J.C. Schmid, H. Hofbauer, H. Stocker, N. Kieberger, T. Bürgler, Sorption enhanced reforming of different fuel types for the production of a 
hydrogen - rich reduction gas, in: SEEP2017-10th Int. Conf. Sustain. Energy Environ. Prot., 2017. doi:10.18690/978-961-286-048-6.25.

[20] I. Martínez, M.C. Romano, Flexible sorption enhanced gasification (SEG) of biomass for the production of synthetic natural gas (SNG) and liquid biofuels: process assessment of stand-alone and power-to-gas plant schemes for SNG production, Energy 113 (2016) 615-630, https://doi.org/10.1016/j.energy.2016.07.026.

[21] I. Martínez, V. Kulakova, G. Grasa, R. Murillo, Experimental investigation on sorption enhanced gasification (SEG) of biomass in a fluidized bed reactor for producing a tailored syngas, Fuel 259 (2020) 116252, , https://doi.org/10.1016/j. fuel.2019.116252.

[22] G. Grasa, R. Murillo, M. Alonso, J.C. Abanades, Application of the random pore model to the carbonation cyclic reaction, AIChE J. 55 (2009) 1246-1255, https:// doi.org/10.1002/aic.11746.

[23] I. Martínez, G. Grasa, R. Murillo, B. Arias, J.C. Abanades, Kinetics of calcination of partially carbonated particles in a Ca-looping system for CO2 capture, Energy Fuels 26 (2012) 1432-1440, https://doi.org/10.1021/ef201525k.

[24] G.S. Grasa, M. Alonso, J.C. Abanades, Sulfation of $\mathrm{CaO}$ particles in a carbonation/ calcination loop to capture CO2, Ind. Eng. Chem. Res. 47 (2008) 1630-1635, https://doi.org/10.1021/ie070937+.

[25] M.P. Aznar, F.A. Gracia-Gorria, J. Corella, Minimum and maximum velocities for fluidization for mixtures of agricultural and forest residues with a second fluidized solid. I. Preliminary data and results with sand-sawdust mixtures, Int. Chem. Eng. 32 (1992) 95-102.

[26] J.P.A. Neeft, Rationale for setup of impinger train as used in the technical specification of sampling and analysis of tar and particles in the product gases of biomass gasification. Technical background document, 2005. http://www.eeci.net/results/ pdf/Rationale-for-setup-of-impinger-trains-v2_Jan05.pdf.

[27] T.J. Schildhauer, S.M.A. Biollaz (Eds.), Synthetic Natural Gas from Coal, Dry Biomass, and power-to-gas applications, Wiley, 2016.

[28] C. Pfeifer, B. Puchner, H. Hofbauer, Comparison of dual fluidized bed steam gasification of biomass with and without selective transport of CO2, Chem. Eng. Sci. 64
(2009) 5073-5083, https://doi.org/10.1016/j.ces.2009.08.014.

[29] J. Fuchs, J.C. Schmid, S. Müller, A.M. Mauerhofer, F. Benedikt, H. Hofbauer, The impact of gasification temperature on the process characteristics of sorption-enhanced reforming of biomass, Biomass Convers. Biorefinery (2019), https://doi. org/10.1007/s13399-019-00439-9.

[30] S. Hafner, M. Schmid, R. Spörl, G. Scheffknecht, Experimental investigation of the sorption enhanced gasification of biomass in a dual fluidized bed pilot plant, in: 27th Eur. Biomass Conf. Exhib., Lisbon, 2019.

[31] J.C. Abanades, E.J. Anthony, J. Wang, J.E. Oakey, Fluidized bed combustion systems integrating $\mathrm{CO} 2$ capture with $\mathrm{CaO}$, Environ. Sci. Technol. 39 (2005) 2861-2866, https://doi.org/10.1021/es0496221.

[32] E.H. Baker, The CaO-CO2 system in the pressure range 1-300 atm, J. Chem. Soc. 70 (1962) 464-470.

[33] J. Herguido, J. Corella, J. González-Saiz, Steam gasification of lignocellulosic residues in a fluidized bed at a small pilot scale. Effect of the type of feedstock, Ind Eng. Chem. Res. 31 (1992) 1274-1282, https://doi.org/10.1021/ie00005a006.

[34] T. Pröll, H. Hofbauer, H2 rich syngas by selective $\mathrm{CO} 2$ removal from biomass gasification in a dual fluidized bed system - process modelling approach, Fuel Process. Technol. 89 (2008) 1207-1217, https://doi.org/10.1016/j.fuproc.2008.05.020.

[35] S. Müller, J. Fuchs, J.C. Schmid, F. Benedikt, H. Hofbauer, Experimental development of sorption enhanced reforming by the use of an advanced gasification test plant, Int. J. Hydrogen Energy 42 (2017) 29694-29707, https://doi.org/10.1016/j. ijhydene.2017.10.119.

[36] M.L. Valderrama Rios, A. Martínez González, E.E.S. Lora, O.A. Almazán del Olmo, Reduction of tar generated during biomass gasification: a review, Biomass Bioenergy 108 (2018) 345-370, https://doi.org/10.1016/j.biombioe.2017.12.002.

[37] U. Wolfesberger, I. Aigner, H. Hofbauer, Tar content and composition in producer gas of fluidized bed gasification of wood-influence of temperature and pressure, Environ. Prog. Sustain. Energy 28 (2009) 372-379, https://doi.org/10.1002/ep. 10387. 